\title{
Age of acquisition and word frequency: Determinants of object-naming speed and accuracy
}

\author{
GAYANE MESCHYAN and ARTURO HERNANDEZ \\ University of California, Santa Barbara, California
}

\begin{abstract}
The combined contributions of word age of acquisition (AoA) and word frequency (rated and objective) to word retrieval speed and accuracy were investigated, using a picture-naming paradigm. Results from two fully factorial studies revealed that both AoA and word frequency reliably facilitate the speed and accuracy of word retrieval. Furthermore, word frequency and AoA interacted across delay $(0,750$, 1,500 , and 2,250 msec) in Experiment 2. This resulted in word frequency's playing a stronger role for lateacquired words across delays. It is concluded that both AoA and word frequency play a fundamental role in lexical retrieval. The results are also consistent with the view that both factors affect the same processing stages.
\end{abstract}

The factors that affect the access and retrieval of lexical items have received a considerable amount of attention in the literature. Initial work suggested that frequency played a fundamental role in the production of words. For example, Oldfield and Wingfield (1965) concluded from their picture-naming study that high-frequency items were accessed more quickly and easily than low-frequency items. More recent studies have also suggested the importance of frequency in the naming of pictures (Jescheniak \& Levelt, 1994). However, other work has suggested that age of acquisition (AoA) and not word frequency (WF), is the primary determinant of the speed of lexical access, retrieval, and production (Barry, Morrison, \& Ellis, 1997; Brysbaert, Lange, \& Wijnendaele, 2000; Ellis \& Morrison, 1998; Gerhand \& Barry, 1998, 1999; Gilhooly \& Gilhooly, 1979; Hodgson \& Ellis, 1998; Morrison, Chappell, \& Ellis, 1997; Morrison \& Ellis, 1995; Morrison, Ellis, \& Quinlan, 1992; Oldfield \& Wingfield, 1965). Our goal in the present study is to examine the combined contributions of AoA and WF to object naming speed and accuracy. Furthermore, we will compare the rate of decay of AoA and WF effects. Our intention is to determine whether AoA and WF affect lexical retrieval tasks in a similar or a different manner.

Early work in picture naming suggested that WF was the primary determinant of the speed of responses (Jescheniak \& Levelt, 1994; Oldfield \& Wingfield, 1965). How-

We are truly grateful to Robert Lorch, Andrew Ellis, and Christopher Barry, as well as to Mary Hegarty and Nancy Collins, for their thoughtful comments on previous versions of this manuscript. Correspondence regarding this article should be addressed to either G. Meschyan or A. Hernandez, Department of Psychology, University of California, Santa Barbara, CA 93106-9660(e-mail: meschyan@ psych.ucsb.edu or hernande@psych.ucsb.edu).

-Accepted by previous editorial team ever, WF and AoA are naturally confounded, with earlyacquired words tending to be higher in frequency than lateacquired words (Carroll \& White, 1973; Gilhooly \& Gilhooly, 1979; Morrison et al., 1992). Furthermore, initial investigations of the simultaneous effects of WF and AoA found an effect of AoA, but no effect of WF on objectnaming speed was found after accounting for effects of AoA (Carroll \& White, 1973; Gilhooly \& Gilhooly, 1979; Morrison et al., 1992). However, subsequent studies have established distinguishable effects of WF and AoA (e.g., Barry et al., 1997; Ellis \& Morrison, 1998, Experiment 1; Lachman, 1973; Lachman, Shaffer, \& Hennrikus, 1974).

A recent study suggests one way in which AoA and WF may combine to influence object naming. Ellis and Lambon Ralph (2000) used connectionist modeling to examine the nature of AoA and its interaction with WF. This was done by using a strong and a weak frequency manipulation. Specifically, frequency of training was modeled at a 10:1 or 3:1 (high vs. low) ratio of exposure. The results revealed a marginal interaction between AoA, pattern frequency (whether it is encountered more or less often), and training frequency (the ratio of high-frequency to low-frequency training). Specifically, results in the high training frequency condition appeared to show larger pattern frequency effects for late-acquired items than for earlyacquired items. Subsequent simulations established that early-acquired words require only occasional exposure to the network in order to maintain a strong lexical representation. Their results show that AoA and frequency may interact in a single experiment, depending on the strength of the frequency interaction. Second, it appears that lateacquired words may be more sensitive to frequency than are early-acquired words.

The present study was designed to investigate the nature of the AoA and frequency interaction. The results from Ellis and Lambon Ralph (2000) suggested that AoA 
has robust effects even in the face of different training frequency parameters. Furthermore, their results suggested that late-acquired words may be more influenced by frequency manipulations than are early-acquired words. These modeling results suggest that AoA should be more robust than frequency across delayed naming intervals. Furthermore, frequency effects may be larger for late-acquired words. To test these hypotheses, we will use a factorial design in which frequency and AoA are crossed.

\section{EXPERIMENT 1}

In Experiment 1, AoA and WF were varied orthogonally to eliminate the natural confounding of the two variables. Neither Ellis and Morrison (1998, Experiment 2) nor Jescheniak and Levelt (1994) had employed this fully factorial design. Furthermore, in their investigation of WF's role in word retrieval speed, Jescheniak and Levelt failed to control for AoA altogether, thus introducing an important confound to their results. Our fully factorial design will overcome the limitations of these two experimental studies while building on the findings from multiple regression studies to reveal whether the two variables also influence word retrieval speed and accuracy in an interactive manner.

In addition to the manipulation of AoA and WF, we manipulated the delay between presentation of an object and a cue to name the object ( 0 vs. $2,200 \mathrm{msec}$ ). This manipulation was based on Ellis and Morrison's (1998, Experiment 2) findings that AoA has an effect on object naming in the immediate condition, but not at a delay of $2,200 \mathrm{msec}$. This is consistent with the view that AoA influences the speed with which spoken word forms are retrieved from the phonological lexicon. Similarly, on the basis of previous multiple regression studies' findings, we expect high-frequency words to be produced more quickly than low-frequency words. However, just as Ellis and Morrison's 2,200-msec delayed naming condition led to the dissipation of the AoA effect, we expect that this delay would also lead to the dissipation of the WF effect. Support for these hypotheses would suggest that the lexemes of late-acquired and low-frequency words (as well as early-acquired and high-frequency words) have reached their activation thresholds by $2,200 \mathrm{msec}$ and have consequently been retrieved from the phonological lexicon.

Given Barry et al.'s (1997) finding of a significant AoA by frequency interaction term in their multiple regression analysis and Ellis and Lambon Ralph's (2000) modeling results, we believe that an AoA $\times$ WF interaction is likely in our immediate naming condition. However, given that the 2,200-msec cue delay would give the lexemes of most, if not all, experimental items the opportunity to reach their activation thresholds, an AoA $\times \mathrm{WF}$ interaction is not expected in the 2,200-msec naming condition. Hence, it will be of interest to see whether a three-way interaction effect is observed.

Lastly, we expect the naming accuracy data to parallel the results for naming latencies. Specifically, we predict that participants will make significantly fewer naming errors on late-acquired and low-frequency words in the delayed naming condition than in the immediate naming condition.

\section{Method}

Participants. Sixty monolingual English-speaking undergraduates at the University of California at Santa Barbara (UCSB) participated in the present study as part of an introductory psychology course requirement. Their mean age was 18.27 years $(S D=0.99)$. Each participant was tested individually in a session that lasted approximately $20 \mathrm{~min}$. All the participants were right-handed.

Design. We used a 2 (cue delay, 0 and 2,200 msec) $\times 2$ (AoA, early and late) $\times 2$ (WF, high and low) mixed design, with cue delay as the between-subjects variable and objective AoA and rated WF as the within-subjects variables. The two dependent variables were picture-naming latencies and accuracy.

Apparatus. The picture stimuli were presented on a Motorola StarMax 3000/180 computer using the PsyScope software (Cohen, MacWhinney, Flatt, \& Provost, 1993) developed at Carnegie Mellon University. Black-and-white line drawings were presented in the center of a 15-in. computer screen. Furthermore, the participants wore a set of headphones with a high-sensitivity microphone attached. The microphone detected verbal responses, and the voice key contained within the button box collected the participants' reaction times (RTs).

Materials. The participants were presented with a total of 160 line drawings obtained primarily from the Snodgrass and Vanderwart (1980) pictures. When some of the pictures from this collection were low in recognizability, we relied on the PicturesPlease (Abbate \& LaChappelle, 1979) picture bank. This measure was taken to ensure the accurate test of our hypotheses. Of the 160 stimuli, half were experimental items, and the remaining 80 were fillers.

Our picture names were chosen from Morrison et al.'s (1997) stimuli (see the Appendix). These researchers had obtained objective AoA measures, as well as measures for other word attributes (e.g., rated frequency, familiarity, visual complexity, name agreement, number of phonemes, and number of syllables) from monolingual British-English-speaking children. Using these measures, the mean for our early AoA words was $23.38(S D=1.03)$, whereas the mean for our late AoA words was $71.88(S D=24.30)$. These objective AoA measures represent the age (in months) at which $75 \%$ of children in Morrison et al.'s study named an item correctly. Although these were British English AoA norms, Ellis and Morrison (1998) have shown that these norms predicted data from Snodgrass and Yuditsky's (1996) American participants, as well as from Welsh participants. Thus, the vocabulary development in different societies seems to be sufficiently similar to allow AoA measures obtained from one society to generalize to another.

Furthermore, our low-frequency words had a mean rating of 2.25 $(S D=0.30)$, whereas our high-frequency words had a mean of 3.84 $(S D=0.35)$. These rated WF values were obtained from Morrison et al. (1997). For objective frequencies of the experimental picture names, please see the Appendix. Objective WF norms were obtained from the Celex Lexical Database (Baayen, Piepenbrock, \& Gulikers, 1995). Each of the four experimental conditions consisted of 20 picture names, and the stimuli in all four conditions were selected to be of very high British English name agreement. However, the items from the four conditions were less well selected for California name agreement, since the late-acquired, high-frequency condition had the lowest California name agreement value (0.84). California name agreement was obtained from 32 UCSB undergraduates, whose responses to the line drawings were recorded on a score sheet by an experimenter. Lastly, given the difficulty we experienced in obtaining a sufficient number of experimental items for the late AoA-high frequency condition, we were forced to have a larger frequency range for our late AoA items (89.5) than for our early AoA items (3). 
Procedure. The participants completed a brief personal information sheet, as well as a handedness measure prior to beginning the experimental session. Upon completion of these forms, the participants were presented with experimental instructions, which appeared on the computer screen. They were instructed to name each picture as quickly as possible without compromising accuracy. They were also told that each picture would be presented only once, in order to discourage them from using the same name for different pictures. If the participants had no questions, they then proceeded with the 10 practice trials. Like the experimental portion of the study, the practice session employed three different cue delays $(0,1,100$, and 2,200 $\mathrm{msec})$. Lastly, to control for order effects, the picture stimuli were presented in a different random order to each participant.

The participants were instructed to clearly articulate the name of each picture only after they had heard the cue "say," which was presented auditorily through the headphones. Furthermore, they were asked to not begin their responses with "um," "er," "uh," etc. If the participants did not follow these instructions consistently, the practice session was repeated. Picture-naming latencies were measured from the onset of the auditory cue "say," and they were recorded by a voice key contained within the button box. The experimenter recorded the participant's response on a score sheet, which was then used to manually code for naming errors and to calculate percent correct values.

For half of the participants, the onset of the cue "say" for all 80 experimental picture stimuli coincided with the onset of the picture, whereas the cue was presented $1,100 \mathrm{msec}$ after the picture for half of the fillers and at a 2,200 msec delay for the remaining fillers. However, for the remaining 30 participants, the onset of the cue for the experimental items occurred 2,200 msec after the presentation of the picture, with 40 of the fillers affiliated with a 0 -msec cue delay and the other 40 fillers associated with a 1,100-msec cue delay. The purpose of the filler items was to keep the participants focused on the task and to keep them from retrieving the words before encountering the cue.

The picture remained on the screen for $5 \mathrm{sec}$ or until the participant made a verbal response, whichever occurred first. The participants initiated the onset of each trial by pressing on the space bar. At the conclusion of the experiment, the participants were verbally debriefed and thanked for their participation. Responses that were superordinates or subordinates to the target response were considered incorrect and were coded accordingly. For example, a superordinate response of "vegetable" to the target word "celery" and the subordinate response "daisy" to the target word "flower" were coded as errors. In addition, semantic associates to the target word (e.g., "cheetah" instead of "leopard") were also coded as incorrect. However, responses that contained the target word (e.g., "needle and thread" for the target "needle") or that were abbreviations of the target word (e.g., "fridge" instead of target "refrigerator") were coded as correct.

\section{Results and Discussion}

Picture-naming latencies. We first conducted 2 (cue delay) $\times 2($ AoA $) \times 2$ (rated $W F)$ mixed design analyses of variance (ANOVAs) by subjects $\left(F_{1}\right)$ and by items $\left(F_{2}\right)$ on the RT dependent measure, where cue delay was the between-subjects variable and objective AoA and rated WF were the within-subjects variables. We used the byitems analysis to learn whether the significant effects we found with the by-subjects analysis were generalizable to other items not used in our experiment. We adopted an $\alpha$ level of .05 for all of our tests of significance.

Although the main effect of AoA was significant, it was qualified by an interaction with cue delay. Table 1 shows, as was expected, that the effect of AoA decreased as cue delay was increased $\left[F_{1}(1,58)=28.61, M S_{\mathrm{e}}=5,263\right.$; $\left.F_{2}(1,76)=13.56, M S_{\mathrm{e}}=7,926\right]$. A planned comparison on this significant interaction effect revealed that earlyacquired words were generated faster than late-acquired words in the immediate naming condition $[F(1,58)=$ 38.62 ], but not in the 2,200-msec cue delay condition $(F<$ $1)$. Nevertheless, Table 1 shows that the WF effect decreased as cue delay increased; this interaction was significant by subjects $\left[F_{1}(1,58)=5.13, M S_{\mathrm{e}}=5,484\right]$, but only approached significance by items $\left[F_{2}(1,76)=3.26\right.$, $\left.M S_{\mathrm{e}}=7,926, p=.08\right]$. Finally, contrary to our expectation, we found no cue delay $\times$ AoA $\times$ WF interaction $(F<1)$. Although the effects of AoA and WF were eliminated by the 2,200-msec delay, there was no evidence of an AoA $X$ WF interaction in the 0-msec delay condition, so the threeway interaction was not significant.

It appears that requiring participants to wait $2,200 \mathrm{msec}$ before naming the picture provides them enough time to access the lexemes of late-acquired and perhaps even lowfrequency words, thus eliminating the effect of AoA and WF in the 2,200-msec delayed naming condition.

Picture-naming accuracy. We also conducted 2 (cue delay) $\times 2($ AoA $) \times 2(\mathrm{WF})$ mixed design ANOVAs by participants and by items on picture-naming accuracy, our second dependent variable. As with the naming latency data, we found that the significant main effect of AoA was qualified by a cue delay $\times$ AoA interaction. The mean naming accuracies in Table 1 reveal that, as was predicted, the AoA effect decreased as cue delay increased $\left[F_{1}(1,58)=7.25, M S_{\mathrm{e}}=19 ; F_{2}(1,76)=5.84\right.$, $\left.M S_{\mathrm{e}}=15\right]$. A planned comparison revealed, however, that even in the 2,200-msec delayed naming condition, early-acquired words were still named significantly more accurately than late-acquired words $[F(1,58)=$ $\left.12.36, M S_{\mathrm{e}}=19\right]$.

Table 1 also shows an interaction of AoA with WF, although the effect was not reliable in the items analysis

Table 1

Mean Naming Times (in Millseconds) and Naming Accuracy Percentages as a Function of Age of Acquisition (AoA), Frequency, and Delay in Experiment 1

\begin{tabular}{|c|c|c|c|c|c|c|c|c|c|c|c|c|}
\hline \multirow[b]{3}{*}{ AoA } & \multicolumn{6}{|c|}{ Frequency at 0 -msec Delay } & \multicolumn{6}{|c|}{ Frequency at 2,200-msec Delay } \\
\hline & \multicolumn{2}{|c|}{ High } & \multicolumn{2}{|c|}{ Low } & \multicolumn{2}{|c|}{ Mean } & \multicolumn{2}{|c|}{ High } & \multicolumn{2}{|c|}{ Low } & \multicolumn{2}{|c|}{ Mean } \\
\hline & $M$ & $\%$ & $M$ & $\%$ & $M$ & $\%$ & $M$ & $\%$ & $M$ & $\%$ & $M$ & $\%$ \\
\hline Early & 913 & 99 & 942 & 96 & 927.5 & 97.5 & 707 & 99 & 683 & 96 & 695 & 97.5 \\
\hline Late & 1,027 & 89 & 1,060 & 92 & $1,043.5$ & 90.5 & 711 & 94 & 711 & 94 & 711 & 94 \\
\hline Mean & 970 & 94 & 1,001 & 94 & & & 709 & 96.5 & 697 & 95 & & \\
\hline
\end{tabular}


$\left[F_{1}(1,58)=17.39, M S_{\mathrm{e}}=19 ; F_{2}(1,76)=1.55, M S_{\mathrm{e}}=\right.$ $140, p=.217]$. Planned comparisons revealed that accuracy was increased more in higher frequency earlyacquired words (99\%) than in early-acquired words that were low in frequency $\left[96 \% ; F(1,58)=8.87, M S_{\mathrm{e}}=19\right]$, whereas there was no difference in accuracy to highfrequency, late-AoA words (92\%) and low-frequency, late-AoA words $(93 \% ; F<1)$. However, the effect of AoA in the high-frequency condition is difficult to interpret, because it might be due to the fact that California name agreement was less in the late-high condition (.84) than in the late-low condition (.92). No other effects were significant. Hence, the age at which an object name is learned is a strong predictor of how accurately that object will be named, whereas the frequency with which the object name is encountered has a more limited effect on the accuracy of object name retrieval.

\section{EXPERIMENT 2}

The results from Experiment 1 revealed that both WF and AoA play a role in picture-naming latencies. Furthermore, it was found that delay results in a reduction of both these effects. These results also indicate that WF and AoA do not interact. However, previous research by Ellis and Lambon Ralph (2000) has found that late-acquired words may be more susceptible to frequency manipulations than are early-acquired words. That is, if late-acquired words have a lower basal activation (or higher activation threshold) than do early-acquired words, it should take longer for these words to become activated. This would predict that late-acquired words should continue to show a frequency effect across delays, whereas early-acquired words should not. In order to test this hypothesis, we incorporated two additional delays ( 750 and $1,500 \mathrm{msec}$ ), which were placed at two intermediate points between the two delays used in Experiment 1. If there is an interaction between AoA and frequency across one of the delay conditions, it would be consistent with the view that magnitude of frequency effects depends on whether the word is learned early or late in life.

\section{Method}

Participants. One hundred and twenty English monolingual undergraduates from UCSB participated in the experiment as part of an introductory psychology course requirement. The mean age of the participants was 18.87 years $(S D=1.43)$. None of these participants had taken part in Experiment 1. As in Experiment 1, all the participants were tested individually in a session that lasted approximately $20 \mathrm{~min}$. All the participants were right-handed.

Design. We used a 4 (cue delay, 0, 750, 1,500, and 2,250 msec) $\times 2$ (objective AoA, early and late) $\times 2$ (rated WF, high and low) mixed factorial design, with cue delay as the between-subjects variable and objective AoA and rated WF as the within-subjects variables. Our two dependent variables were object-naming latencies, measured in milliseconds, and naming accuracy. Thirty participants took part in each cue delay condition.

Materials. We used the same picture stimuli and picture names as those used in Experiment 1. However, we added two new fillers, "bed" and "key," to make it a total of 82 fillers. None of the filler items were included in the statistical analysis. The filler "key" was always assigned to the same cue delay condition as the experimental stimuli in order to have a total of 81 items in that delay condition.

Procedure. The procedure of Experiment 2 was identical to that of Experiment 1, except for the distribution of items across delay conditions. In both the experiments, all of the experimental items were presented at the same delay for a given participant (comprising $50 \%$ of all the items), and the filler items were evenly distributed across the remaining delays. However, the 80 filler trials of Experiment 1 were divided among two delay conditions (40 trials per delay, or $25 \%$ of all the trials), whereas the 81 filler trials of Experiment 2 were divided among three delay conditions (i.e., 27 trials per delay, or $16.7 \%$ of all the trials).

\section{Results and Discussion}

Picture-naming latencies. We conducted by-subjects and by-items 4 (cue delay) $\times 2$ (AoA) $\times 2(\mathrm{WF})$ mixed design ANOVAs on participants' naming latencies (see Table 2). Again, an $\alpha$ of .05 was used for all the analyses. Although both delay $\times \mathrm{WF}\left[F_{1}(3,116)=11.55, M S_{\mathrm{e}}=\right.$ 3,$\left.813 ; F_{2}(3,228)=8.20, M S_{\mathrm{e}}=4,020\right]$ and delay $\times$ AoA $\left[F_{1}(3,116)=19.33, M S_{\mathrm{e}}=4,554 ; F_{2}(3,228)=18.55\right.$, $\left.M S_{\mathrm{e}}=4,020\right]$ interactions were significant, they were qualified by a three-way delay $\times$ AoA $\times$ WF interaction $\left[F_{1}(3,116)=2.55, M S_{\mathrm{e}}=4,061, p=.06 ; F_{2}(3,228)=\right.$ $\left.2.23, M S_{\mathrm{e}}=4,020, p=.09\right]$. This confirms our prediction that the frequency continues to speed the recognition of

Table 2

Mean Naming Times (in Milliseconds) and Naming Accuracy Percentages as a Function of Age of Acquisition (AoA), Frequency, and Delay in Experiment 2

\begin{tabular}{|c|c|c|c|c|c|c|c|c|c|c|c|c|}
\hline \multirow[b]{3}{*}{ AoA } & \multicolumn{6}{|c|}{ Frequency at 0-msec Delay } & \multicolumn{6}{|c|}{ Frequency at 750 -msec Delay } \\
\hline & \multicolumn{2}{|c|}{ High } & \multicolumn{2}{|c|}{ Low } & \multicolumn{2}{|c|}{ Mean } & \multicolumn{2}{|c|}{ High } & \multicolumn{2}{|c|}{ Low } & \multicolumn{2}{|c|}{ Mean } \\
\hline & $M$ & $\%$ & $M$ & $\%$ & $M$ & $\%$ & $M$ & $\%$ & $M$ & $\%$ & $M$ & $\%$ \\
\hline Early & 993 & 99 & 1,059 & 96 & 1,026 & 97.5 & 752 & 99 & 746.0 & 96.0 & 749 & 97.5 \\
\hline Late & 1,118 & 87 & 1,202 & 89 & 1,160 & 88 & 763 & 87 & 813 & 91 & 788 & 89 \\
\hline \multirow[t]{4}{*}{ Mean } & $1,055.5$ & 93 & $1,130.5$ & 92.5 & & & 757.5 & 93 & 779.5 & 93.5 & & \\
\hline & \multicolumn{6}{|c|}{ Frequency at 1,500 -msec Delay } & \multicolumn{6}{|c|}{ Frequency at 2,250-msec Delay } \\
\hline & \multicolumn{2}{|c|}{ High } & \multicolumn{2}{|c|}{ Low } & \multicolumn{2}{|c|}{ Mean } & \multicolumn{2}{|c|}{ High } & \multicolumn{2}{|c|}{ Low } & \multicolumn{2}{|c|}{ Mean } \\
\hline & $M$ & $\%$ & $M$ & $\%$ & $M$ & $\%$ & $M$ & $\%$ & $M$ & $\%$ & $M$ & $\%$ \\
\hline Early & 745 & 99 & 737 & 95 & 741 & 97. & 719 & 98 & 734 & 95 & 726.5 & 96.5 \\
\hline Late & 766 & 87 & 748 & 94 & 757 & 90.5 & 762 & 87 & 748 & 93 & 755 & 90 \\
\hline Mean & 755.5 & 93 & 742.5 & 94.5 & & & 740.5 & 92.5 & 741 & 94 & & \\
\hline
\end{tabular}


late-acquired words across delays. Planned tests of the simple effect of frequency support the trends evident in Figure 1. For early-acquired words, the effect of frequency is reliable only at the 0 -msec delay condition $[F(1,29)=$ $\left.14.89, M S_{\mathrm{e}}=4,388.48\right]$. For late-acquired words, the effect of frequency was reliable at both the 0 - and 750-msec delay condition $\left[F(1,29)=23.54, M S_{\mathrm{e}}=5,504\right.$, and $\left.F(1,29)=9.65, M S_{\mathrm{e}}=4,039\right]$.

These results suggest that learning words early in life helps us retrieve these words more quickly. However, when a word is learned later in life, high frequency compensates for this late-AoA disadvantage by increasing the base-rate activation level of the word's lexeme. As we can see in Table 2, late-acquired object names that are high in frequency have already been retrieved by $750 \mathrm{msec}$. By contrast, words that are low in frequency and learned later in life have still not been completely retrieved by this delay. Hence, AoA and WF interact with delay. Rated WF makes an important contribution for words that are learned later in life.

Finally, regression analyses were performed in order to look at the role of AoA, rated frequency, and objective frequency on RT. The method used was that of Lorch and Myers (1990), in which a regression is calculated for within-subjects designs. This was done only at the 0 -msec delay condition. The results revealed that AoA $[F(1,29)=$ $\left.137.63, M S_{\mathrm{e}}=4,470\right]$ and rated frequency $[F(1,29)=$ $\left.17.61, M S_{\mathrm{e}}=5,592\right]$ were significant predictors of RT. However, objective frequency was not a significant predictor $\left[F(1,29)=2.99, M S_{\mathrm{e}}=8,797\right]$. This extends the findings of the factorial design in Experiment 2 by show-

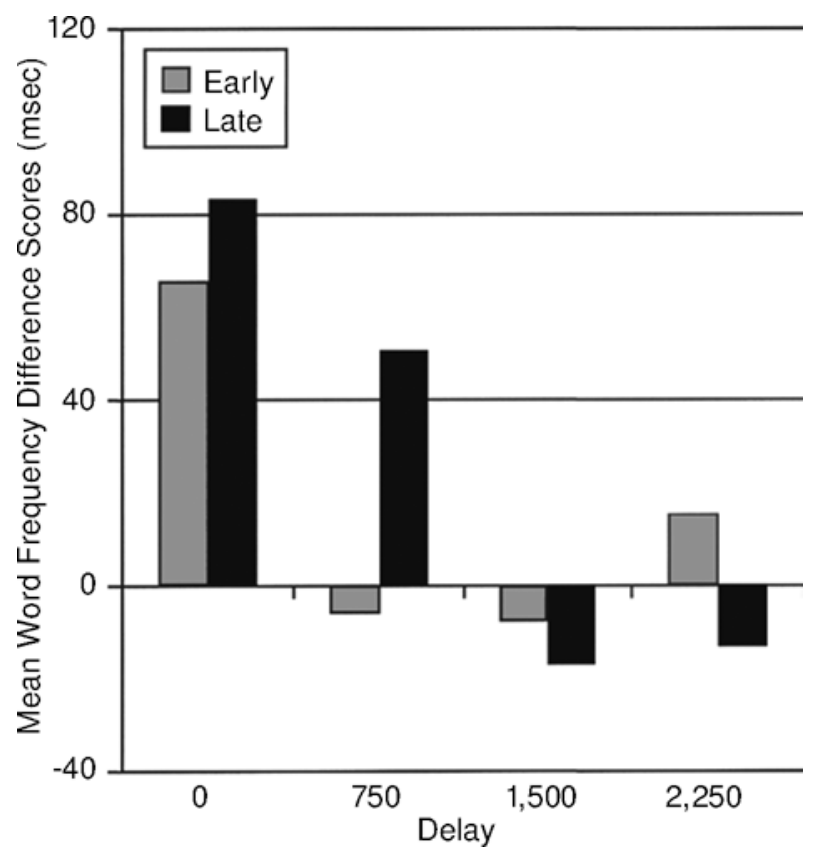

Figure 1. Mean word frequency difference scores (in milliseconds) as a function of word age of acquisition (early, late) and naming delay. ing that rated frequency is a stronger predictor of RTs than is objective frequency.

Picture-naming accuracy. Our by-subjects and byitems 4 (cue delay) $\times 2($ AoA $) \times 2$ (rated WF) mixed design ANOVAs on picture-naming accuracy revealed that the participants were more accurate on early-acquired words $(97 \%)$ than on late-acquired words $\left[89 \% ; F_{1}(1,116)=\right.$ $\left.232.95, M S_{\mathrm{e}}=31 ; F_{2}(1,76)=9.60, M S_{\mathrm{e}}=498\right]$. This main effect of AoA is consistent with our results for Experiment 1 . However, unlike Experiment 1, we can see in Table 2 that the AoA effect decreased significantly as delay increased $\left[F_{1}(3,116)=2.49, M S_{\mathrm{e}}=31, p=.06\right.$; $\left.F_{2}(3,228)=2.93, M S_{\mathrm{e}}=17\right]$. On the other hand, rated WF did not appear to influence picture-naming accuracy, since the participants were equally accurate on lowfrequency words (93\%) and high-frequency words [93\%; $F_{1}(1,116)=1.73, M S_{\mathrm{e}}=25, p=.19 ; F_{2}(1,76)=0.06$, $\left.M S_{\mathrm{e}}=498, p=.81\right]$.

The only other effect to approach significance was the AoA $\times$ WF interaction, although the test was not reliable against item variance $\left[F_{1}(1,116)=72.82, M S_{\mathrm{e}}=28\right.$; $\left.F_{2}(1,76)=2.76, M S_{\mathrm{e}}=498, p=.10\right]$. The nature of the interaction was that the effect of AoA was greater for highfrequency words (99\% vs. $87 \%$ ) than for low-frequency words $(95.5 \%$ vs. $92 \%)$. Like Experiment 1 , the effect of AoA in the high-frequency condition is difficult to interpret, because it might be due to the fact that California name agreement was less in the late-high condition (.84) than in the late-low condition (.92). No other effects were significant. These results are consistent with those observed in Experiment 1.

\section{GENERAL DISCUSSION}

Our two experiments contribute uniquely to the word retrieval literature in the following ways. First, by simultaneously varying both AoA and WF in a fully factorial design, we examined the independent contributions of AoA and WF to object-naming speed and accuracy, as well as their interactive contributions to these dependent variables. Second, we employed varying delayed naming conditions to more thoroughly investigate the role of word AoA and WF in word retrieval speed and accuracy.

The results of Experiment 1 revealed that both word AoA and rated frequency make independent contributions to word retrieval speed when participants are asked to prepare their response immediately upon encountering the picture. However, having participants wait $2,200 \mathrm{msec}$ before picture naming allowed the retrieval of late-acquired and low-rated-frequency words. Furthermore, the interaction between naming delay and AoA not only corroborated the findings of Ellis and Morrison (1998, Experiment 2), but also, along with the delay $\times$ rated frequency interaction, motivated us to investigate the time course of the word AoA and rated frequency effects in Experiment 2 . Our use of the varying delayed naming conditions (i.e., $0,750,1,500$, and $2,250 \mathrm{msec}$ ) enabled us to obtain 
a more detailed view of the nature of the contribution of word AoA and WF to word retrieval.

AoA and WF. A second issue of importance is the presence of an interaction between WF, AoA, and delay. But, how do we account for the interaction? These results are quite compatible with both classic and connectionist views of language representation. In the classic view, both WF and AoA contribute to a lowering of basal lexical activation. How often a lexical item is seen and how early it is learned serve to reduce the amount of activation necessary for a word to reach its threshold. In connectionist models (e.g., Ellis \& Lambon Ralph, 2000), this would be conceptualized as a change in the weights of hidden units. To date, Ellis and Lambon Ralph's account is the most complete account of AoA effects. However, their account does not necessarily preclude an account in terms of logogens (Morton, 1969), activation thresholds, or verification times (Levelt, Roelofs, \& Meyer, 1999).

The first question raised by our study focuses on whether frequency and AoA affect the same processing mechanism or stage during picture naming. Although our results are not definitive in this respect, they do tend to fit better with the view that AoA and frequency affect the same processing stage. Specifically, both of these variables are responsible for making the access of the phonological word form easier (for further discussion, see Levelt et al., 1999). Rated word frequency interacted with AoA, and both facilitated picture naming. Furthermore, their interaction across delays indicates that frequency matters more for late-acquired words. The implication is that latelearned words have weaker lexical representations and thus benefit more from frequency than do early-acquired words. Consistent with the view of Ellis and Lambon Ralph (2000), we suggest that frequency and AoA affect the same processing stage and are most likely the product of the same lexical process(es).

The second implication of our data has to do with whether AoA and frequency are accounted for by similar mechanisms in development. Some have suggested that AoA and frequency may be the product of cumulative frequency (Gilhooly, 1984; Lewis, 1999; Lewis, Gerhand, \& Ellis, 2001). That is, the AoA effect is simply the product of frequency over a lifetime, and frequency is how often one encounters the word. Our results are not definitive evidence against this view. However, they are more supportive of the view that the frequency and AoA effects are not the product of cumulative exposure to a word. The fact that frequency differentially affects late-learned words across delays is consistent with the view that each of these factors is not the product of the same mechanism during learning (see Lewis et al., 2001, for an alternative account).

One way to further understand learning history would be to look at second-language learners. This population would provide an interesting test case for the importance of AoA and its effects on speed of lexical retrieval and production. Specifically, the lexical items would be learned late in life. Hence, frequency should play a strong role in lexical access. However, if early-learned concepts influ- ence later learning, the mapping of these items onto already existing concepts should be easier if those concepts are more robust. If Ellis and Lambon Ralph (2000) are correct, we should expect to see late learners of a second language show the same pattern of effects as that observed in early learners (perhaps a bit stronger). Hence, the importance of AoA most likely also influences which lexical items have a head start, even for learners of a second language.

Finally, although not the main goal, the present study revealed similarities between rated and objective WF. Specifically, both forms of WF predict RTs. Furthermore, both appear to be weaker than AoA. More recent studies suggest that rated frequency may capture information in addition to that seen in objective frequency measures (Balota, Pilotti, $\&$ Cortese, 2001). Our results suggest that rated frequency is a better predictor of RTs than is objective frequency. Future studies are needed to further understand how rated and objective frequency interact with AoA.

\section{REFERENCES}

Abbate, M. S., \& LaChappelle, N. B. (1979). Pictures, please: A language supplement. Tucson, AZ: Communication Skill Builders.

BaAyen, R. H., Piepenbrock, R, \& Gulikers, L. (1995). The CELEX lexical database (Release 2) [CD-ROM]. Philadelphia: University of Pennsylvania, Linguistic Data Consortium [Distributor].

Balota, D. A., Pilotti, M., \& Cortese, M. J. (2001). Subjective frequency estimates for 2,938 monosyllabic words. Memory \& Cognition, 29, 639-647.

Barry, C., Morrison, C. M., \& Ellis, A. W. (1997). Naming the Snodgrass and Vanderwart pictures: Effects of age of acquisition, frequency, and name agreement. Quarterly Journal of Experimental Psychology, 50, 560-585.

Brysbaert, M., Lange, M., \& Wijnendaele, I. V. (2000). The effects of age-of-acquisition and frequency-of-occurrence in visual word recognition: Further evidence from the Dutch language. European Journal of Cognitive Psychology, 12, 65-85.

Carroll, J. B., \& White, M. N. (1973). Word frequency and age of acquisition as determiners of picture-naming latency. Quarterly Journal of Experimental Psychology, 25, 85-95.

Cohen, J., MacWhinney, B., Flatt, M., \& Provost, J. (1993). PsyScope: An interactive graphic system for designing and controlling experiments in the psychology laboratory using Macintosh computers. Behavior Research Methods, Instruments, \& Computers, 25 , 257-271.

Ellis, A. W., \& Lambon Ralph, M. A. (2000). Age of acquisition effects in adult lexical processing reflect loss of plasticity in maturing systems: Insights from connectionist networks. Journal of Experimental Psychology: Learning, Memory, \& Cognition, 26, 1103-1123.

Ellis, A. W., \& Morrison, C. M. (1998). Real age-of-acquisition effects in lexical retrieval. Journal of Experimental Psychology: Learning, Memory, \& Cognition, 24, 515-523.

GeRHAND, S., \& BARRY, C. (1998). Word frequency effects in oral reading are not merely age-of-acquisition effects in disguise. Journal of Experimental Psychology: Learning, Memory, \& Cognition, 24, 267-283.

Gerhand, S., \& BARry, C. (1999). Age-of-acquisition and frequency effects in speeded word naming. Cognition, 73, B27-B36.

Gilhooly, K. J. (1984). Word age-of-acquisition and residence time in lexical memory as factors in word naming. Current Psychological Research \& Reviews, 3, 24-31.

Gilhooly, K. J., \& Gilhooly, M. L. (1979). Age-of-acquisition effects in lexical and episodic memory tasks. Memory \& Cognition, 7, 214-223.

Hodgson, C., \& Ellis, A. W. (1998). Last in, first to go: Age of acquisition and naming in the elderly. Brain \& Language, 64, 146-163.

Jescheniak, J. D., \& LeVelt, W. J. M. (1994). Word frequency effects 
in speech production: Retrieval of syntactic information and of phonological form. Journal of Experimental Psychology: Learning, Memory, \& Cognition, 20, 824-843.

LACHMAN, R. (1973). Uncertainty effects on time to access the internal lexicon. Journal of Experimental Psychology, 99, 199-208.

Lachman, R., Shaffer, J. P., \& Hennrikus, D. (1974). Language and cognition: Effects of stimulus codability, name-word frequency, and age of acquisition on lexical reaction time. Journal of Verbal Learning \& Verbal Behavior, 13, 613-625.

Levelt, W. J. M., Roelofs, A., \& Meyer, A. S. (1999). A theory of lexical access in speech production. Behavioral \& Brain Sciences, 22, 1-75.

LewIS, M. B. (1999). Age of acquisition in face categorisation: Is there an instance-based account? Cognition, 71, B23-B39.

Lewis, M. B., Gerhand, S., \& Ellis, H. D. (2001). Re-evaluating ageof-acquisition effects: Are they simply cumulative-frequency effects? Cognition, 78, 189-205.

LORCH, R. F., \& MYers, J. L. (1990). Regression analyses of repeated measures data in cognitive research. Journal of Experimental Psychology: Learning, Memory, \& Cognition, 16, 149-157.

Morrison, C. M., Chappell, T. D., \& Ellis, A. W. (1997). Age of ac- quisition norms for a large set of object names and their relation to adult estimates and other variables. Quarterly Journal of Experimental Psychology, 50B, 528-559.

Morrison, C. M., \& Ellis, A. W. (1995). Roles of word frequency and age of acquisition in word naming and lexical decision. Journal of Experimental Psychology: Learning, Memory, \& Cognition, 21, 116-133. Morrison, C. M., Ellis, A. W., \& Quinlan, P. T. (1992). Age of acquisition, not word frequency, affects object naming, not object recognition. Memory \& Cognition, 20, 705-714.

Morton, J. (1969). Interaction of information in word recognition. Psychological Review, 76, 165-178.

OldField, R. C., \& Wingfield, A. (1965). Response latencies in naming objects. Quarterly Journal of Experimental Psychology, 17, 273-281.

SNODGRASS, J. G., \& VANDERWART, M. (1980). A standardized set of 260 pictures: Norms for name agreement, image agreement, familiarity, and visual complexity. Journal of Experimental Psychology: Human Learning \& Memory, 6, 174-215.

SnOdgrass, J. G., \& YudiTsKy, T. (1996). Naming times for the Snodgrass and Vanderwart pictures. Behavior Research Methods, Instruments, \& Computers, 28, 516-536.

\section{APPENDIX}

Experimental Picture Names Used in Experiments 1 and 2

\begin{tabular}{|c|c|c|c|c|c|c|c|c|c|c|c|c|c|c|c|c|c|}
\hline \multicolumn{9}{|c|}{ Early-Low } & \multicolumn{9}{|c|}{ Early-High } \\
\hline Stimulus & $\mathrm{oA}$ & $\mathrm{VC}$ & $\mathrm{Na}-\mathrm{C}$ & $\mathrm{Na}-\mathrm{B}$ & $\mathrm{rF}$ & $\mathrm{oF}$ & $1 \mathrm{~m}$ & $\mathrm{~F}$ & Stimulus & $\mathrm{oA}$ & $\mathrm{VC}$ & $\mathrm{Na}-\mathrm{C}$ & $\mathrm{Na}-\mathrm{B}$ & $\mathrm{rF}$ & $\mathrm{oF}$ & $\operatorname{lm}$ & $\mathrm{F}$ \\
\hline butterfly & 23 & 4.1 & 1.0 & 1.0 & 2.6 & 2 & 6.3 & 2.7 & apple & 22 & 1.8 & 1.00 & 1.0 & 3.9 & 5 & 6.5 & 4.5 \\
\hline cow & 23 & 3.9 & 1.0 & 1.0 & 2.9 & 14 & 6.6 & 3.2 & banana & 23 & 1.3 & 1.00 & 0.9 & 3.7 & 5 & 6.6 & 3.7 \\
\hline elephant & 23 & 4.1 & 1.0 & 1.0 & 2.1 & 9 & 6.7 & 2.2 & book & 22 & 2.5 & 0.97 & 1.0 & 4.7 & 766 & 6.1 & 4.7 \\
\hline frog & 23 & 3.6 & 1.0 & 0.9 & 2.3 & 13 & 6.4 & 2.4 & boot & 23 & 2.1 & 0.94 & 1.0 & 4.2 & 19 & 6.1 & 4.2 \\
\hline hammer & 25 & 2.6 & 1.0 & 1.0 & 2.3 & 8 & 6.1 & 2.8 & bus & 23 & 4.2 & 0.97 & 0.8 & 3.9 & 64 & 6.6 & 4.0 \\
\hline helicopter & 23 & 4.2 & 1.0 & 0.8 & 2.0 & 5 & 6.4 & 2.0 & car & 22 & 3.9 & 0.97 & 1.0 & 4.3 & 366 & 6.7 & 4.5 \\
\hline horse & 23 & 3.5 & 1.0 & 1.0 & 2.8 & 40 & 6.7 & 2.8 & chair & 22 & 2.1 & 1.00 & 1.0 & 4.0 & 26 & 6.5 & 4.8 \\
\hline ladder & 25 & 2.6 & 1.0 & 1.0 & 2.4 & 12 & 6.7 & 2.6 & clock & 22 & 2.6 & 0.91 & 1.0 & 3.9 & 17 & 6.3 & 4.2 \\
\hline lion & 23 & 3.3 & 1.0 & 1.0 & 2.0 & 17 & 6.6 & 1.9 & fork & 23 & 2.2 & 1.00 & 1.0 & 4.0 & 8 & 6.4 & 4.6 \\
\hline monkey & 25 & 3.2 & 1.0 & 0.9 & 2.1 & 7 & 6.5 & 2.1 & glasses & 23 & 2.6 & 0.88 & 0.9 & 3.9 & 7 & 6.3 & 3.8 \\
\hline mouse & 23 & 3.0 & 0.5 & 0.8 & 2.3 & 12 & 6.7 & 2.6 & hand & 23 & 2.8 & 0.91 & 1.0 & 4.0 & 309 & 6.3 & 4.6 \\
\hline pig & 23 & 2.7 & 1.0 & 1.0 & 2.5 & 10 & 6.8 & 2.4 & house & 22 & 2.4 & 0.91 & 1.0 & 4.0 & 471 & 6.7 & 3.8 \\
\hline rabbit & 22 & 2.7 & 0.9 & 1.0 & 2.8 & 8 & 6.6 & 2.8 & knife & 23 & 2.0 & 0.91 & 1.0 & 4.3 & 14 & 6.5 & 4.8 \\
\hline slide & 22 & 4.0 & 0.9 & 1.0 & 2.5 & 27 & 5.9 & 2.9 & pants & 25 & 2.3 & 1.00 & 1.0 & 3.9 & 4 & 6.2 & 4.9 \\
\hline snake & 25 & 3.6 & 1.0 & 1.0 & 2.3 & 9 & 6.7 & 2.1 & shoe & 22 & 3.2 & 0.97 & 1.0 & 4.3 & 26 & 6.4 & 4.7 \\
\hline snowman & 23 & 2.5 & 1.0 & 1.0 & 2.2 & 1 & 6.6 & 2.2 & sock & 23 & 1.8 & 1.00 & 1.0 & 4.1 & 9 & 6.2 & 4.7 \\
\hline squirrel & 25 & 2.8 & 0.9 & 1.0 & 2.2 & 1 & 6.3 & 2.6 & spoon & 22 & 1.9 & 1.00 & 0.9 & 4.1 & 2 & 6.3 & 4.6 \\
\hline tractor & 23 & 3.6 & 0.9 & 1.0 & 2.4 & 5 & 6.2 & 2.8 & sun & 23 & 1.5 & 0.94 & 1.0 & 4.0 & 64 & 6.7 & 4.5 \\
\hline umbrella & 23 & 3.0 & 1.0 & 1.0 & 2.5 & 11 & 6.6 & 3.4 & table & 22 & 2.1 & 0.97 & 1.0 & 4.2 & 87 & 6.6 & 4.5 \\
\hline wheel & 25 & 3.4 & 0.9 & 0.9 & 3.0 & 46 & 6.5 & 2.7 & window & 25 & 3.4 & 1.00 & 1.0 & 3.9 & 58 & 6.2 & 4.6 \\
\hline$M$ & 23.8 & 3.29 & 0.95 & 0.96 & 2.39 & 12.9 & 6.47 & 2.56 & $M$ & 23.0 & 2.4 & 0.94 & 1.0 & 4 & 116.4 & 6.4 & 4.4 \\
\hline$S D$ & 0.97 & 0.57 & .011 & 0.06 & 0.28 & 11.9 & 0.23 & 0.4 & $S D$ & 0.96 & 0.75 & 0.04 & 0.05 & 0.23 & 203.8 & 0.2 & 0.36 \\
\hline
\end{tabular}


APPENDIX (Continued)

\begin{tabular}{|c|c|c|c|c|c|c|c|c|c|c|c|c|c|c|c|c|c|}
\hline \multicolumn{9}{|c|}{ Late-Low } & \multicolumn{9}{|c|}{ Late-High } \\
\hline Stimulus & oA & $\mathrm{VC}$ & $\mathrm{Na}-\mathrm{C}$ & $\mathrm{Na}-\mathrm{B}$ & $\mathrm{rF}$ & $\mathrm{oF}$ & $\operatorname{lm}$ & $\mathrm{F}$ & Stimulus & $\mathrm{oA}$ & $\mathrm{VC}$ & $\mathrm{Na}-\mathrm{C}$ & $\mathrm{Na}-\mathrm{B}$ & $\mathrm{rF}$ & $\mathrm{oF}$ & $\operatorname{lm}$ & $\mathrm{F}$ \\
\hline$\overline{\text { anchor }}$ & 103 & 2.3 & 0.9 & 1.0 & 1.8 & 1 & 6.0 & 1.7 & boy & 57 & 3.9 & 0.53 & 1.0 & 4.1 & 146 & 6.3 & 4.5 \\
\hline ant & 63 & 3.7 & 0.9 & 0.9 & 2.5 & 2 & 5.9 & 2.8 & camera & 51 & 2.7 & 1.00 & 1.0 & 3.4 & 29 & 6.0 & 4.0 \\
\hline broom & 87 & 2.5 & 1.0 & 0.7 & 2.2 & 1 & 6.3 & 2.7 & cloud & 57 & 1.2 & 0.84 & 1.0 & 3.4 & 17 & 6.6 & 4.1 \\
\hline celery & 140 & 4.3 & 0.8 & 1.0 & 2.3 & 1 & 5.5 & 2.5 & coat & 69 & 2.5 & 0.59 & 1.0 & 4.0 & 16 & 5.8 & 3.8 \\
\hline crab & 51 & 3.8 & 0.9 & 1.0 & 2.0 & 1 & 6.4 & 2.6 & desk & 87 & 3.3 & 1.00 & 0.9 & 3.6 & 26 & 6.2 & 4.6 \\
\hline goat & 57 & 2.8 & 0.9 & 1.0 & 2.0 & 2 & 6.3 & 2.0 & fly & 57 & 3.6 & 0.97 & 1.0 & 3.1 & 12 & 5.6 & 3.2 \\
\hline gorilla & 63 & 3.2 & 0.8 & 0.9 & 1.9 & 1 & 6.1 & 1.6 & hair & 57 & 2.9 & 0.97 & 1.0 & 4.3 & 57 & 5.8 & 4.5 \\
\hline king & 57 & 3.7 & 0.9 & 1.0 & 2.1 & 50 & 6.4 & 3.0 & jacket & 57 & 3.9 & 0.22 & 0.9 & 3.6 & 7 & 6.0 & 3.7 \\
\hline lightbulb & 103 & 3.3 & 1.0 & 0.8 & 2.5 & 1 & 6.3 & 4.3 & lamp & 75 & 1.9 & 0.97 & 0.9 & 3.6 & 7 & 6.0 & 3.7 \\
\hline peacock & 93 & 4.3 & 0.8 & 1.0 & 2.1 & 2 & 6.3 & 1.9 & mushroom & 63 & 3.1 & 1.00 & 0.8 & 3.3 & 4 & 6.2 & 3.2 \\
\hline pipe & 75 & 2.0 & 1.0 & 1.0 & 2.1 & 28 & 5.7 & 2.2 & nose & 57 & 1.4 & 0.91 & 1.0 & 3.6 & 39 & 5.8 & 4.6 \\
\hline pliers & 127 & 2.3 & 0.7 & 0.9 & 1.9 & 1 & 5.9 & 2.3 & onion & 69 & 2.9 & 1.00 & 1.0 & 3.5 & 2 & 6.2 & 4.0 \\
\hline raccoon & 140 & 4.4 & 1.0 & 0.9 & 1.6 & 1 & & 1.8 & er & 115 & & 0.47 & 1 & 3.6 & 3 & 5.5 & 3.6 \\
\hline saw & 69 & 2.3 & 1.0 & 1.0 & 2.1 & 1 & 6.2 & 2.4 & potato & 75 & 2.2 & 1.00 & 0.8 & 3.9 & 7 & 6.2 & 3.9 \\
\hline screwdriver & 69 & 1.9 & 1.0 & 1.0 & 2.5 & 1 & 6.0 & 2.7 & refrigerator & 57 & 2.4 & 1.00 & 0.7 & 4.3 & 2 & 6.2 & 4.5 \\
\hline violin & 63 & 3.8 & 0.9 & 1.0 & 2.2 & 12 & 6.4 & 2.1 & ring & 51 & 2.6 & 0.97 & 1.0 & 3.5 & 58 & 6.0 & 3.8 \\
\hline well & 87 & 3.8 & 0.9 & 0.9 & 2.2 & 12 & 4.9 & 3.8 & shirt & 57 & 3.0 & 0.88 & 1.0 & 3.8 & 15 & 6.3 & 4.1 \\
\hline whale & 57 & 2.9 & 0.9 & 1.0 & 2.2 & 1 & 6.4 & 3.2 & skirt & 57 & 3.2 & 0.75 & 0.9 & 3.3 & 12 & 6.1 & 3.6 \\
\hline whistle & 51 & 2.3 & 1.0 & 1.0 & 2.4 & 5 & 5.6 & 2.5 & toaster & 51 & 3.5 & 1.00 & 1.0 & 3.4 & 0 & 6.0 & 3.9 \\
\hline witch & 51 & 3.3 & 1.0 & 1.0 & 2.3 & 5 & 6.7 & 2.4 & tomato & 69 & 2.0 & 0.78 & 1.0 & 3.8 & 3 & 6.5 & 3.6 \\
\hline$M$ & 79.9 & 3.12 & 0.92 & 0.93 & 2.11 & 6.45 & 6.01 & 2.52 & $M$ & 63.9 & 2.71 & 0.84 & 0.93 & 3.63 & 23.15 & 6.04 & 3.96 \\
\hline$S D$ & 29.1 & 0.81 & 0.09 & 0.09 & 0.25 & 12.2 & 0.44 & 0.67 & $S D$ & 15.2 & 0.75 & 0.22 & 0.08 & 0.33 & 33.65 & 0.28 & 0.42 \\
\hline
\end{tabular}

Note-oA, objective age of acquisition in months (Morrison, Chappell, \& Ellis, 1997); VC, visual complexity; Na-C, California name agreement; Na-B, British English name agreement; rF, rated frequency (Morrison et al., 1997); oF, objective frequency (Celex); lm, rated imageability; F, rated familiarity.

(Manuscript received July 15, 1999;

revision accepted for publication October 29, 2001.) 